International Journal of Sanskrit Research 2021; 7(5): 182-183

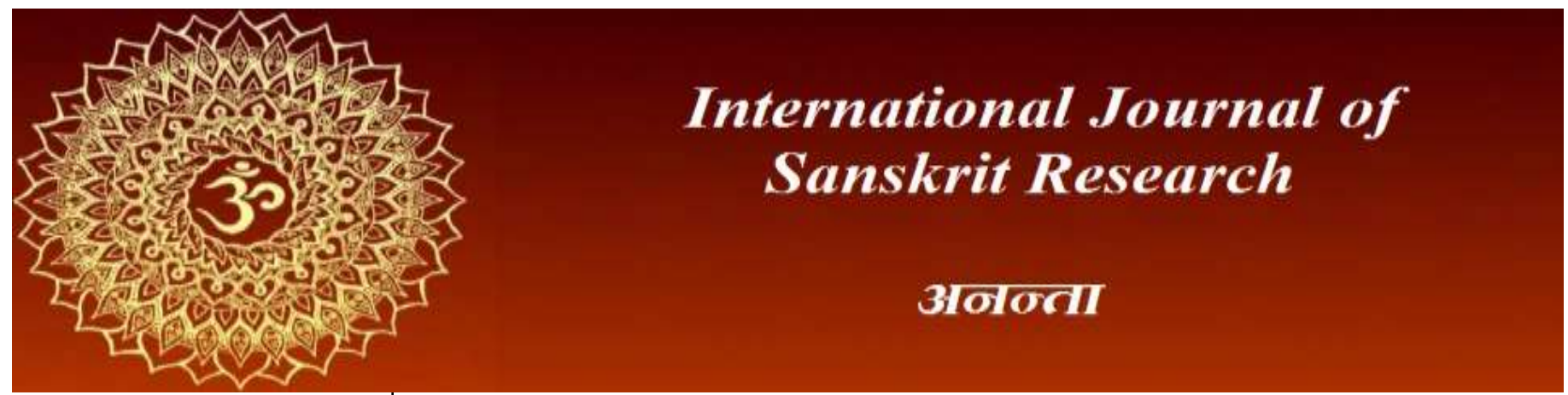

ISSN: 2394-7519

IJSR 2021; 7(5): 182-183

(C) 2021 IJSR

www.anantaajournal.com

Received: 15-06-2021

Accepted: 02-08-2021

ओमप्रकाश बरबडे

संस्कृत-विभाग, पुण्यश्लोक

अहिल्यादेवी होळकर सोलापूर

विद्यापीठ, सोलापूर, महाराष्ट्र, भारत
Corresponding Author: ओमप्रकाश बरबडे

संस्कृत-विभाग, पुण्यश्लोक अहिल्यादेवी होळकर सोलापूर विद्यापीठ, सोलापूर, महाराष्ट्र, भारत

\section{व्याकरणवेद्या: लोकव्यवहाराः}

\section{ओमप्रकाश बरबडे}

\section{प्रस्तावना}

अज्ञानान्धस्य लोकस्य ज्ञानाज़जनशाकया।

चक्षुरुन्मीलितं येन तस्मै पाणिनये नमः।।

मानवः सामाजिकः वर्त्तते। तन्मनसि प्रकृतिं परिस्थितिं वा दृष्ट्वा विविधविचाराः समुत्पद्यन्ते, तान् विचारान् सम्प्रेषयितुं भाषां प्रयुङ्क्ते। मानवः स्वविचारान् सम्प्रेषयितुं भाषां द्विधा प्रयुङ्क्ते, मौखिकरुपेण लिखितरुपेण च। भाषायाः विचाराणां प्रकटनमात्रेण, सम्प्रेषणमात्रेण वा कोऽपि निश्चितः शुद्धस्वरुपः स्थिरतां न प्राप्नोति। भाषायां शुद्धतां स्वरुपस्थायित्वं च सुनिश्चेतुं तथा च भाषां सुव्यवस्थातुं नियमबद्धयोजना आवश्यकी, तां नियमबद्धयोजनामेव वयं व्याकरणं भाषामहे।

वयमेतमेकेन लौकिकोदाहरणेनावगच्छामः, यथा अस्मद्देशे नानाप्रवृत्तिजनानां निवासोऽस्ति तान् सर्वान् एकसूत्रे आनेतुं सुव्यवस्थातुं च संविधानं व्याकरणवत्कार्य करोति। पूर्व भाषा भवति परं च व्याकरणं भवति। व्याकरणपरिभाषाविषये विविधाचार्याणां मतमप्यस्मिन्स्थले उचित भाति। पाणिनिः व्याकरणपदं वि+आङ् उपसर्गपूर्वक "डुकृज् करणे"1 धातोः "ल्युट् च"2 सूत्रेण ल्युट् प्रत्यये कृते सिद्धयति। यस्योत्पत्तिः भवति" "व्याक्रियन्ते व्युत्पाद्यन्ते निष्पाद्यन्ते (प्रकृतिप्रत्ययविभागकल्पनया) शब्दाः अनेन इति व्याकरणम्" महाभाष्यकारः पतंजलिः गदति यत् "सूत्रे व्याकरणे"3 अर्थात् नियमः एव व्याकरणमस्ति. यल्लोके भाषारुपेण प्रयुज्यमानः शुद्धप्रयोगरेव व्याकरणेन नियम्यते. भर्तृहरिः स्ववाक्यपदीये व्याकरणस्य महिमां कुर्वन् कथयति-

"आसन्नं ब्रह्मणस्तस्य, तपसामुत्तमं तपः ।
प्रथमं छन्दसामडगं, प्राहुर्व्याकरणं बुधाः 4 ।।

अर्थात्-तस्य ब्रह्मणः आसन्नं=समीपस्थं तपसामुत्तमं तप: छन्दसा= वेदानां प्रथमाङ्गं एताद्ग्गुणेर्युक्तं बुधाः व्याकरणं कथयन्ति। व्याकरणन्तु केवलं प्रयोगशुद्धतां, शब्दशुद्धतां च बोधयति। शब्दार्थसम्बन्धस्तु लोकतः एव ज्ञायते। व्याकरणाधारिताः आचार्येः बहवः ग्रन्थाः विरचितास्सन्ति, तेषु ग्रन्थेषु याः विद्यमानाः कारिकाः यानि सूत्राणि वार्त्तिकानि च सन्ति, तैः सूत्रेः ताभिः कारिकाभिश्च घुणाक्षरन्यायेन बहुविधलोकव्यवहाराः ज्ञायन्ते, किन्तु व्याकरणस्य प्रधानकार्य प्रयोगशुद्धता वर्त्तते। उक्तमपि वाक्यपदीयकारेण स्वग्रन्थे-

"अर्थप्रवृत्तितत्वानां शब्दा एव निबन्धनम्।

तत्वावबोधः शब्दानां नास्ति व्याकरणादृते"

अर्थात्- लोके यदा कस्यापि अर्थे (विषये) मनुष्यप्रवृत्तिः भवति तदा शब्दः एव विभिन्नगुणयुक्तस्यार्थस्य एकशब्देन निबन्धनं करोति, किन्तु शब्दानां तत्वावबोधः अर्थात् प्रयोगशुद्धता, शब्दशुद्धता तु व्याकरणादृते न ज्ञायते। अतः लोके शुद्धप्रयोगाय पदे-पदे व्याकरणप्रयोजनं विद्यते। पाणिनेः पतंजलेः परिभाषाकारस्य ग्रन्थेषु बहुत्र लोकव्यवहारबोधकानि सूत्राणि, वार्त्तिकानि, कारिकाश्च सन्ति। यथा- परिभाषेन्दुशेखरे प्रथमपरिभाषा विद्यते-

"व्याख्यानतो विशेषप्रतिपत्तिः न हि सन्देहादलक्षणम्"6

अर्थात्- लोके सर्वकारः कामपि नियमोद्घोषणां करोति अथवा कोऽपि कामपि वात्त्तां कथयति, तत्र सर्वत्र व्याख्यानतः = (विश्लेषणतः विवेकतः वा) एव विशेषज्ञानस्य अथवा तस्याभिप्रायस्य निश्चयः करणीयः, केवलं सन्देहमात्रेण तस्य निराकरणन्न करणीयमिति लोकव्यवहारोऽनया परिभाषया ज्ञायते। 
अस्मद्दैनिकव्यवहारे विविधकार्याणि भवन्ति तत्र कानिचन प्रधानानि, कानिचन च अप्रधानानि (अमुख्यानि) तेषु कुत्र प्रामुख्यं दातव्यमिति लोकव्यवहारं बोधयति परिभाषेषा-

"गोणमुख्ययोः मुख्ये कार्यसम्प्रत्यय:"7

"प्रधानाप्रधानयोः प्रधाने कार्यसम्प्रत्यय:"8

अर्थात्- यत्र प्रधानकार्याणामप्रधानकार्याणाज्चोभयोः एकैव कार्यकालः, तदा प्रधानकार्ये मनः स्थितिः प्रधानता च दातव्या। गृहस्थपरिवारोऽस्ति, तस्य पुत्रैकैवास्ति, सः गृहस्थः तत्पुत्रेण लोके कथं व्यवहरति इति पाणिनिसूत्रमवगमयति-"आद्यन्तवदेकस्मिन्" 9 अर्थात यदि परिवारे पुत्रद्वयमस्ति चेत् ज्येष्ठकनिष्ठयोः व्यवहारः भवति, किन्तु परिवारे एकैव पुत्रश्चेत् सः एकपुत्रे एव ज्येष्ठकनिष्ठयो: व्यवहारं करोति, यथा- अयमेव मम ज्येष्ठपुत्रः कनिष्ठपुत्रश्चायमेव विद्यते इति ।

दैनिकव्यवहारे जातिशब्दान् वयं प्रयुज्जमहे, जातिनाम अयं एकोऽर्थः तत्रैकवचनं करणीयं किन्तु तत्र बहुवचनमपि लोकव्यवहारे दृश्यते, तं लोकव्यवहारं बोधयति पाणिनेरिदं सूत्रम्-

\section{"जात्याख्यायामेकस्मिन् बहुवचनमन्यतरस्याम्"10}

अर्थात्- शब्देन जातेराख्यायामेकस्मिनर्थे बहुवचनमपि कर्त्तु शक्यते इति लोकव्यवहारः वैकल्पिकः। यथा- ब्राहमणैक: गच्छति चेदपि वयं वदामः "ब्राह्मणाः गच्छन्ति इति। लोकव्यवहारे वयं पश्यामोऽनुभवामश्च यत् एककार्यकरणस्यानेके विधयः विद्यन्ते, किन्तु कार्यमनेन विधिना एव करणीयमिति नियमः एकैव भवति। उभयोः कः श्रेष्ठ: इति लोकव्यवहारं बोधयति परिभाषेयं-

\section{"विधिनियमप्रसङ्गे विधिरेव ज्यायान्"11}

अर्थात्- विधेः नियमस्य च प्रसङ्गे विधिरेव ज्यायान् भवति यथा पाठनस्यानेके विधयः भवन्ति, सामूहिक विधि:, व्याख्यान विधिः, मान्टेसर विधिः इत्यादयः। नियमस्तु व्यख्यानविधिनैव पाठनीयमिति नियमः, अन्यविधिना न इति। तत्र लोकव्यवहारं बोधयति परिभाषेयं यत् स्थित्यनुसारं विधिपरिवर्त्तनीया यतः सा एव नियमात् श्रेष्ठाउस्ति इति लोकव्यवहारे दृश्यते।

वयं दैनिकव्यवहारे बहूनां स्तोत्राणां मन्त्राणां केवलं पारायणं कुर्मः नार्थ जानीमः। तत्र महाभाष्यकारः वदति यत् पारायणात् अर्थज्ञता ज्यायसी इति लोकव्यवहारे दृश्यते तं बोधयति कारिकेयं-

"यदधीतमविज्ञातं निगदेनैव शब्दते।

अनग्नाविव शुष्कैधो न तज्वलति कर्हिचित्' 12

अर्थात - यदधीतमविज्ञातं $=$ केवलं पारायणमात्रमेव क्रियते, तत्कदापि लाभाय न भवति।

यथा काष्ठास्थाग्निः अग्निसंयोगेन विना कदापि न ज्वलति, तथैव मन्त्रस्थाभिप्रायः अर्थेन विना ज्ञातः न भविष्यति। लोके वयं पश्यामः यत् बहुषु नूतनार्थेषु वस्तुषु नूतनशब्दानां प्रयोगः भवति, तथा च पुरा भिन्नार्थेषु प्रयुक्तानां बहूनां शब्दानां वर्त्तमानकाले भिन्नार्थे प्रयोग: भवति, शब्दार्थसम्बन्धस्यास्य कारणं लोकव्यवहारमेवास्तीति बोधयति वार्तिकमिदम्-"सिद्धे शब्दार्थसम्बन्धे"13 अर्थात् शब्दार्थसम्बन्धः नित्योऽस्ति, सम्बन्धस्यास्य च ज्ञानं लोकतः एव भवति।

यथा- कुशलशब्दः "कुशान् लातीति= कुशल:" इत्यस्मिन् अर्थे प्रयुक्तः किन्तु अधुना निपुणार्थे रुढः, इति ज्ञानं लोकव्यवहारतः भवति इति वार्तिकमिदम् बोधयति। एवमेवानेके लोकव्यवहाराः व्याकरणाद् ज्ञायन्ते यथा-
अर्थात्- सहचरिते असहचरिते च सहचरितेन सह लोकव्यवहारः। (रुप्यकादिदानं करणीयमिति) "अर्थवदग्रहणे नानर्थकस्य"15 अर्थात्येन न्यूनपरिश्रमेणात्यधिकः लाभः भवति तस्यैव सार्थकलाभस्य लोके ग्रहणं दृश्यते, अनर्थकस्यालाभस्य ग्रहणं न दृश्यते न च करणीयमिति लोकव्यवहारं बोधयति.

\section{निष्कर्ष}

निष्कर्षरुपेणेवं वक्तुं शक्यते यत् व्याकरणलोकाधारितमस्ति, लोके प्रयुक्तान् शुद्धप्रयोगान् शब्दशुद्धतां च व्याकरणं नियमेषु बह्नाति। व्याकरणनियमानाधृत्य बहुभिराचार्येः बहवः ग्रन्था: सूत्ररुपेण, कारिकारुपेण, वार्त्तिकरुपेण, गद्यरुपेण च विरचितास्सन्ति, तेषु ग्रन्थेषु बहव्यः कारिकाः सूत्राणि च लोकव्यवहारबोधकास्सन्ति, तेषु केषांचिदेवोद्धरणमत्रास्ति । अतः साररुपेण लेखने मन्ये इयमतिशयोक्तिः न भविष्यति, यत् व्याकरणं प्रयोगशुद्धतया व्याकरणशुद्धतया सह लोकव्यवहारमपि बोधयति इति।

\section{सन्दर्भ सूचि}

1. डुकृज् करणे- धातुपाठ. भ्वा. धातु-642

2. ल्युट् च- अष्टा. अ.3 पाद. 3 सूत्र-115

3. सूत्रे व्याकरणे.- महाभाष्य. पस्पशा. पृ. 43

4. आसन्नं ब्रह्मणस्तस्य.-वाक्यपदीय. ब्रह्म. कारिका.11 पृ. 105

5. अर्थप्रवृत्तितत्वानां-- वाक्यपदीय. ब्रहम. कारिका. 13 पृ. 113

6. व्याख्यानतो विशेष.-पारिभाषिक. परिभाषा-1 पृ.1

7. गोणमुख्ययो:-- पारिभाषिक. परिभाषा-16 पृ. 24

8. प्रधानाप्रधानयो:- पारिभाषिक. परिभाषा-86 पृ.119

9. आद्यन्तवदे.- अष्टा. अध्या. 1 पाद. 1 सूत्र-20

10. जात्याख्यायामेक.- अष्टा. अध्या. 1 पाद. 2 सूत्र-58

11. विधिनियमप.- पारिभाषिक. परिभाषा-144 पृ. 161

12. यदधीतमविज्ञातं-- महाभाष्य. पस्पशा. पृ. 13

13. सिद्धे शब्दार्थ.- महाभाष्य. पस्पशा. पृ. 27

14. सहचरितासहचरितयो:- पारिभाषिक. परिभाषा-91 पृ.125

15. अर्थवदग्रहणे.- पारिभाषिक. परिभाषा-15 पृ. 22

"सहचरितासहचरितयो: सहचरितस्यैव ग्रहणम्"14 